\title{
BMJ Open Analysis of caesarean sections using Robson 10-group classification system in a university hospital in eastern Ethiopia: a cross-sectional study
}

\author{
Abera Kenay Tura, ${ }^{1,2}$ Olga Pijpers, ${ }^{3}$ Myrna de Man, ${ }^{3}$ Myrthe Cleveringa, ${ }^{3}$ \\ Ingeborg Koopmans, ${ }^{3}$ Tadesse Gure, ${ }^{4,5}$ Jelle Stekelenburg ${ }^{6,7}$
}

To cite: Tura AK, Pijpers 0 , de Man M, et al. Analysis of caesarean sections using Robson 10-group classification system in a university hospital in eastern Ethiopia: a crosssectional study. BMJ Open 2018;8:e020520. doi:10.1136/ bmjopen-2017-020520

\section{- Prepublication history for} this paper is available online. To view these files, please visit the journal online (http://dx.doi. org/10.1136/bmjopen-2017020520).

$\mathrm{OP}, \mathrm{MM}, \mathrm{MC}$ and IK contributed equally.

Received 8 November 2017 Revised 16 February 2018 Accepted 23 February 2018
Check for updates

For numbered affiliations see end of article.

Correspondence to Abera Kenay Tura; daberaf@gmail.com

\section{ABSTRACT}

Objective To analyse caesarean section (CS) using Robson 10-group classification system in an Ethiopian university hospital.

Design Cross-sectional study.

Setting A university hospital in eastern, Ethiopia. Participants 980 women who underwent CS from January 2016 to April 2017.

Main outcome Robson groups (1-10-based on gestational age, fetal presentation, number of fetus, onset of labour and history of CS) and indications for CS.

Results Robson group 3 (multiparous women with single cephalic full-term pregnancy in spontaneous labour with no history of CS), group 5 (multiparous women with single cephalic full-term pregnancy with history of CS) and group 1 (single cephalic nulliparous women full-term pregnancy in spontaneous labour) were the major contributors to the overall CS at $21.4 \%, 21.1 \%$ and $19.3 \%$, respectively. The three major indications for CS were fetal compromise (mainly fetal distress), obstructed labour (mainly cephalopelvic disproportion) and previous CS.

Conclusion Robson groups 3, 5 and 1 were the major contributors to the overall CS rate. Fetal compromise, obstructed labour and previous CS were the underlying indications for performing CS. Further study is required to assess the appropriateness of the indications and to reduce CS among the low-risk groups (groups 1 and 3).

\section{INTRODUCTION}

Over the last few decades, the global caesarean section (CS) rate has significantly increased and reached an unprecedented level. ${ }^{1}$ Although there is no specific rate of recommended CS rate, ${ }^{2}$ no improvement in maternal and neonatal outcomes was observed in CS rates above $10 \% .^{34} \mathrm{CS}$ is performed when vaginal delivery is not possible or contraindicated. ${ }^{5}$ In such cases, not performing a CS could endanger the life of the mother and the fetus. However, CS is also performed without medical reasons or with imprecise indications such as obstructed labour, with intact membranes. ${ }^{6}$

\section{Strengths and limitations of this study}

Conducted in a university hospital with large catchment population.

- Analysed caesarean section over 16 months to avoid seasonal variations.

- Because of retrospective design, some relevant information might be missing.

- Most of the women were referred cases with underlying complications and may not be generalised to general population.

- Single-hospital (with large burden of referred cases) study, might be less generalisable.

This potentially life-saving procedure is not without risk and might become life-threatening in the index or future pregnancies for both the mother and child. Immediate and long-term complications of CS including increased risk of maternal mortality and morbidity, increased need for blood transfusion, longer hospitalisation, postpartum infections, retained placenta, stillbirths and postpartum haemorrhage were reported. ${ }^{7-9}$

Although the national population-based CS rate of Ethiopia is still one of the lowest in the world $(2 \%),{ }^{10}$ a national review conducted in 2011 indicated a high CS rate in facilities ( $15 \%$ in public facilities vs $46.1 \%$ in for-profit centres), ${ }^{11}$ which is expected to be higher now because of the general increase in the CS rate. A study conducted in eastern Ethiopia indicated a CS rate of $34.3 \%$ (26.6\% in public facilities and $58.7 \%$ in private hospitals). ${ }^{12}$ The population-based study, from the Demographic and Health Survey, is low since many women in need of CS do never reach facilities (institutional delivery rate of $26 \%$ ). ${ }^{10}$ This indicates that some women might be exposed to unnecessary CS while others do not get the CS they need. ${ }^{6}$ For example, CS is highest among women with at least secondary 
education, living in urban areas or are rich compared with their counterparts. ${ }^{13}{ }^{14}$ In urban settings and among the rich, there is a concern, in many countries, that the intervention is being over utilised and unnecessary interventions are done. In rural settings, however, lack of access to adequately staffed and equipped health institutions for providing essential obstetric surgery is contributing largely to maternal mortality and complications. ${ }^{15}$

The challenge is to keep CS rates low while maintaining safe outcomes for the mother and infant. This requires continuous auditing of CS. Three different classifications-based on primary clinical indications, the degree of urgency or absolute need for caesarean delivery, and Robson classification-have been reported as a framework for auditing CS. ${ }^{16}$ A systematic review comparing different classifications concluded that the Robson classification is optimal for monitoring $\mathrm{CS}^{17}$ and the WHO recommended Robson classification as a global standard tool for monitoring CS. ${ }^{2}$ The Robson classification also called the Ten Group Classification System (TGCS), classifies CS into 10 mutually exclusive and exhaustive groups based on the category of the pregnancy, the previous obstetric record of the woman, the course of labour and delivery, and the gestational age of the pregnancy. ${ }^{18}$ Although the application of the TGCS and its importance for targeting population and reducing CS rates has been previously noted, ${ }^{19-21}$ there is no study in Ethiopia and contribution of different groups to the overall CS is unknown. In Ethiopia, where most facilities are situated in urban centres and high CS rate in referral hospitals is registered, ${ }^{12} 22$ an audit of CS deliveries using the TGCS is important to know which groups of women are mainly contributing to the increase in CS rate. The aim of this study was to analyse CSs using the TGCS and identify indications for CS in Hiwot Fana Specialized University Hospital in eastern Ethiopia.

\section{METHODS}

\section{Study design and participants}

This study was conducted as part of a PhD study on severe maternal morbidity and mortality in eastern Ethiopia. We conducted a cross-sectional study to analyse all CS performed from January 2016 to April 2017 at the department of obstetrics of Hiwot Fana Specialised University Hospital (HFSUH) Harar, eastern Ethiopia. The study population included all women who underwent CS in the hospital during the specified period. Laparotomy for uterine rupture and files with missing information were excluded. The identity of women who underwent CS was obtained from the delivery logbook, admission and discharge register and operation logbook. The admission and discharge register and delivery logbook contain information about all women who delivered in the hospital regardless of mode of delivery (vaginal, CS) while the operation logbook contains only information about women who underwent CS. Using the medical registration number of each woman, we accessed all CS files performed during the study period.

\section{Study setting}

HFSUH is a tertiary referral hospital affiliated with the College of Health and Medical Sciences, Haramaya University, Ethiopia where around 3500 deliveries took place annually. The hospital serves both referred complicated cases and self-referred uncomplicated births. During the study period, the department of obstetrics was run by seven consultants, eight residents and 16 (nurse) midwives. The department has its operation theatre for obstetric cases.

\section{Variables}

For each CS case, we collected data on maternal characteristics (age, history of CS, parity and gravidity), pregnancy-related information (gestational age, fetal presentation, number of fetus and onset of labour) and maternal and fetal outcomes at discharge (complications, fifth minute APGAR score, birth weight, fetal and maternal status). Maternal complications included presence of a potentially life-threatening conditions (severe postpartum haemorrhage, severe pre-eclampsia, eclampsia, ruptured uterus, sepsis or severe systemic infections); admission to the intensive care unit other than for routine postoperative recovery; or receiving blood products. Presence of any life-threatening complication (including maternal near miss or deaths) was assessed at discharge. Maternal near miss refers to a woman who nearly died (developed organ dysfunction) but survived the complication, based on the WHO definition. ${ }^{23}$ The dependent variable was the Robson classification group. The 10 groups and their characteristics are shown in box 1. Fetal presentations were classified as cephalic, breech or transverse/oblique. Gestational age was categorised as a term ( $\geq 37$ weeks) or preterm ( $<37$ weeks). Gestational age is assessed using early prenatal ultrasound or last menstrual period. In case of no early ultrasound and unknown last menstrual period, a combination of physical examination, third trimester

\section{Box 1 Robson's 10-group classification}

\section{Description}

1. Nulliparous, single cephalic, $\geq 37$ weeks, in spontaneous labour.

2. Nulliparous, single cephalic, $\geq 37$ weeks, induced or caesarean section (CS) before labour.

3. Multiparous (excluding previous CS), single cephalic, $\geq 37$ weeks, in spontaneous labour.

4. Multiparous (excluding previous CS), single cephalic, $>37$ weeks, induced or CS before labour.

5. Previous CS, single cephalic, $\geq 37$ weeks.

6. All nulliparous breeches.

7. All multiparous breeches (including previous CS).

8. All multiple pregnancies (including previous CS).

9. All abnormal lies (including previous CS).

10. All single cephalic, $<37$ weeks (including previous CS). 


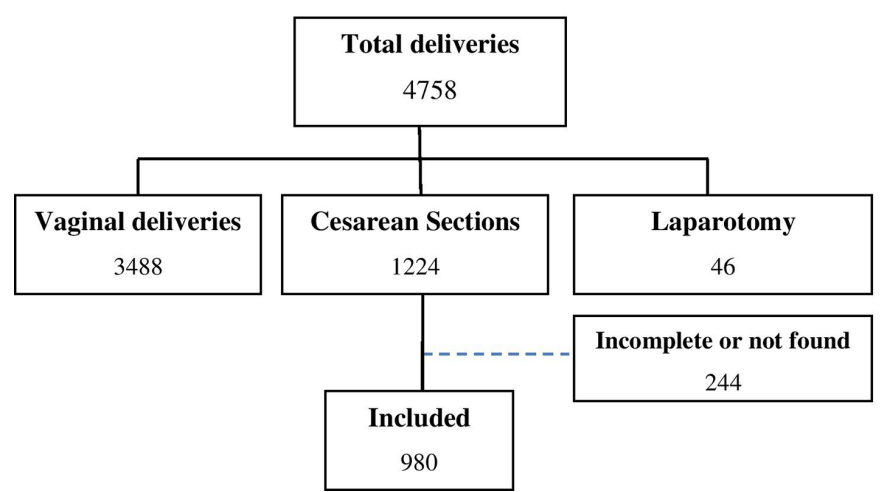

Figure 1 Flow chart of the study in Hiwot Fana Specialised University Hospital, 2017.

ultrasound and estimated fetal weight is used for estimation of gestational age. For cases with undocumented gestational age, we used a birth weight of $\geq 2500 \mathrm{gm}$ as a proxy to term pregnancy. The course of pregnancy was categorised as spontaneous and induced/CS before labour. Number of parity was classified as nulliparous or multiparous. The number of fetuses was categorised as singleton or multiple pregnancies.

\section{Data collection}

Data were collected by medical students (OP, MM, MC, IK) from University of Groningen, the Netherlands. Data collectors were trained and supervised by the first author (AKT). All data quality, indications and eligibility of cases were confirmed by a senior obstetrician (TG). All CSs during the study period were retrieved from the operation register and were double checked with delivery logbook and admission and discharge registers. Completeness of data was checked by the first author (AKT).

\section{Data processing and analysis}

All completed data were entered using EpiData V.3.1 (http:// www.epidata.dk) and analysed using SPSS V.23. Descriptive statistics of study participants and variables was conducted. The Robson group was assigned based on four obstetric concepts (with their parameters)—category of the pregnancy, previous obstetric history, course of labour and gestational age. ${ }^{18}$ Missing files in the archive room and cases with incomplete information were excluded. All reported indications were classified as absolute maternal and non-absolute indications using the recommendations by Stanton et al. ${ }^{16}$ Absolute maternal indications included obstructed labour, major antepartum haemorrhage (APH), malpresentation (transverse, oblique and brow) and uterine rupture in hierarchical order. Non-absolute indications include fetal compromise, previous CS, failure to progress, breech, severe pre-eclampsia and eclampsia (with no hierarchy). Results were presented as frequencies, percentages, means and SD.

\section{RESULTS}

During the study period, there were 4758 deliveries, of which $1224(25.7 \%)$ were CS. After excluding incomplete cases $(n=96)$ and missing files (148), 980 cases were included in the final analysis (figure 1). The mean age of participants was $26.3( \pm 5.7)$ years. Mean duration of hospitalisation was $6.3( \pm 3.9)$ days. A quarter of study participants $(25 \%)$ had a potentially life-threatening condition, including $2.8 \%$ women with maternal near miss and nine maternal deaths. The mean gestational age was $37.7( \pm 2.2)$ weeks. Sociodemographic characteristics and obstetric conditions are summarised in table 1.

\section{Robson TGCS}

In our study, single cephalic multiparous women at term in spontaneous labour with no previous history of CS (group 3) were the highest contributors to the overall CS rate, contributing $21.4 \%$ of all CS. The second highest contributors were women with a single cephalic presentation at term and previous CS (group 5) contributing $21.1 \%$ to the overall CS. The third highest contributors were single cephalic nulliparous women at term and in spontaneous labour (group 1) with 19.3\%. All women with breech, transverse or oblique presentation (groups 6,7 , and 9 combined) contributed $13.8 \%$ to the overall CS. All single cephalic women in preterm (group 10) contributed $6.2 \%$ of all the CS (figure 2).

\section{Indications for performing CS}

As shown in figure 3, the main indications for performing CS were fetal compromise (fetal distress, cord prolapse or intrauterine growth retardation), obstructed labour (cephalopelvic disproportion, fetal macrosomia or unspecified disproportions) and previous CS. Indications per Robson group are shown in table 2. Absolute maternal indications (obstructed labour, major APH, malpresentation or uterine rupture) were the leading indications only in three groups: group 3 (obstructed labour), group 9 (malpresentation) and group 10 (major APH). In the other groups, non-absolute indications were the leading indications for performing CS-group 1 (fetal compromise), groups 2 and 4 (failure to progress), group 5 (previous CS), groups 6,7 and 8 (breech presentation). In general, CS was performed for absolute maternal indications in $36.6 \%$ (359/980) of cases (table 2). Diagrammatic representation of contribution of each indication within the groups is presented in figure 4 .

\section{DISCUSSION}

Our study showed that groups 3, 5, and 1 were the major contributors to the overall CS rate. This indicates high CS rate both in primary (groups 1 and 3) and secondary (group 5) CS. The study also showed that only one-third (36.6\%) of the CS were performed for absolute maternal indications. A quarter of the women had a potentially life-threatening condition (including nine maternal deaths), resulting in admission for more than 7 days in $29.2 \%$ of the women. Since a majority of births in Ethiopia are occurring at home, ${ }^{10}$ most births in the hospital 
Table 1 Sociodemographic and obstetric conditions of study participants

\begin{tabular}{|c|c|c|}
\hline Variables & $\mathbf{n}$ & $\%$ \\
\hline \multicolumn{3}{|l|}{ Age (years) } \\
\hline$<20$ & 78 & 7.9 \\
\hline $20-35$ & 850 & 86.7 \\
\hline$>35$ & 53 & 5.4 \\
\hline \multicolumn{3}{|c|}{ Duration of hospitalisation } \\
\hline $1-7$ days & 674 & 70.8 \\
\hline$>7$ days & 278 & 29.2 \\
\hline
\end{tabular}

Type of CS

\begin{tabular}{|c|c|c|}
\hline Elective/planned & 72 & 7.4 \\
\hline Emergency & 908 & 92.6 \\
\hline \multicolumn{3}{|l|}{ Gravidity } \\
\hline 1 & 305 & 31.1 \\
\hline $2-4$ & 421 & 43.0 \\
\hline$>4$ & 254 & 25.9 \\
\hline \multicolumn{3}{|l|}{ Parity } \\
\hline 0 & 319 & 32.5 \\
\hline $1-4$ & 473 & 48.3 \\
\hline$>4$ & 188 & 19.2 \\
\hline \multicolumn{3}{|l|}{ Gestational age } \\
\hline Preterm ( $\leqq 36$ weeks) & 111 & 11.3 \\
\hline Term (37-42 weeks) & 863 & 88.1 \\
\hline Post-term (>42 weeks) & 4 & 0.6 \\
\hline \multicolumn{3}{|l|}{ Onset of labour } \\
\hline Spontaneous & 728 & 74.4 \\
\hline Induced/CS before labour & 251 & 25.6 \\
\hline \multicolumn{3}{|l|}{ Fetal presentation } \\
\hline Cephalic & 808 & 82.4 \\
\hline Breech & 135 & 13.8 \\
\hline Transverse/oblique/brow/others & 37 & 3.8 \\
\hline \multicolumn{3}{|l|}{ Fetal status at birth } \\
\hline Alive & 924 & 94.3 \\
\hline Stillbirths & 56 & 5.7 \\
\hline \multicolumn{3}{|l|}{ Apgar score at $5 \mathrm{~min}$} \\
\hline$<7$ & 89 & 9.5 \\
\hline$>7$ & 836 & 90.5 \\
\hline
\end{tabular}

Birth weight (g)

$\begin{array}{lrr}<2500 & 157 & 16.1 \\ 2500-4000 & 779 & 80.1 \\ >4000 & 37 & 3.8\end{array}$

Potential life-threatening conditions $(n=245)$

\begin{tabular}{lrr} 
Severe postpartum hemorrhage & 18 & 1.8 \\
\hline Severe pre-eclampsia & 122 & 12.4 \\
Eclampsia & 62 & 6.3 \\
\hline Ruptured uterus & 6 & 0.6 \\
\hline
\end{tabular}

Continued

\begin{tabular}{|c|c|c|}
\hline Variables & $\mathbf{n}$ & $\%$ \\
\hline Sepsis & 14 & 1.4 \\
\hline Transfusion of blood (>1 unit RBC) & 107 & 10.9 \\
\hline \multicolumn{3}{|l|}{ Maternal status at discharge } \\
\hline Alive & 971 & 99.1 \\
\hline Dead & 9 & 0.9 \\
\hline
\end{tabular}

CS, caesarean section; RBC, red blood cells.

are among women with complications or women living in the urban areas nearby the hospital.

Our findings are in line with a classification applied in hospitals from Tanzania and South Africa ${ }^{24} 25$ where the three major groups (1,3 and 5) were the same, though in a different order. In South Africa, groups 1, 5 and 3 while in Tanzania groups 1, 3 and 5 were the leading contributors. This may be related to variations in population demographics and overall CS rates. ${ }^{26}$ The contribution of group 3 could be justifiable in our study since the majority of the CS were performed for absolute maternal indications (obstructed labour and major antepartum haemorrhage).

In a study from a university hospital in Cote d'Ivoire, however, the most common groups were groups 1,2 and $3 .{ }^{27}$ The importance of group 2 (nulliparous single cephalic term pregnancy, induced or caesarean before labour) in the study from Cote d'Ivoire could be explained by variations in indications for inductions of vaginal birth or CS in the two settings. In most high-income settings, groups 5, 2 and 1 are the major contributors to overall CS rate unlike the studies from low-income settings. ${ }^{28-31}$ The variations between high-income settings and our study may be related to fertility trends and, therefore, stronger presentation of groups 1 and 2 in high-income settings, compared with stronger presentation of multiparous women (group 3) in our low-resource setting with high fertility rates. ${ }^{10}{ }^{26}$ Induction of labour (group 2) is more frequently practised in high-income settings ranging from $8.3 \%$ in Latvia to $33 \%$ in Wallonia (Belgium) compared with $4.4 \%$ in Africa. ${ }^{32} 33$ Risk selection in antenatal care is better developed, which leads to more frequently indicating induction of labour. ${ }^{34}$ Barriers for induction of labour in low-resource settings might be the unavailability of facilities to perform CS in case of failed induction. ${ }^{35}$ The fact that group 5 women were one of the major contributors both in high-income and low-income settings indicates the importance of preventing primary caesarean if a meaningful reduction in overall CS rate is to be achieved. In a study from Tanzania both primary and secondary CS were rising overtime. ${ }^{24}$

The strength of this study is the inclusion of all CS performed over 16 months in a referral hospital covering large catchment area. Although the hospital is serving both uncomplicated births and women with complications, the majority of the cases were cases of women referred with 


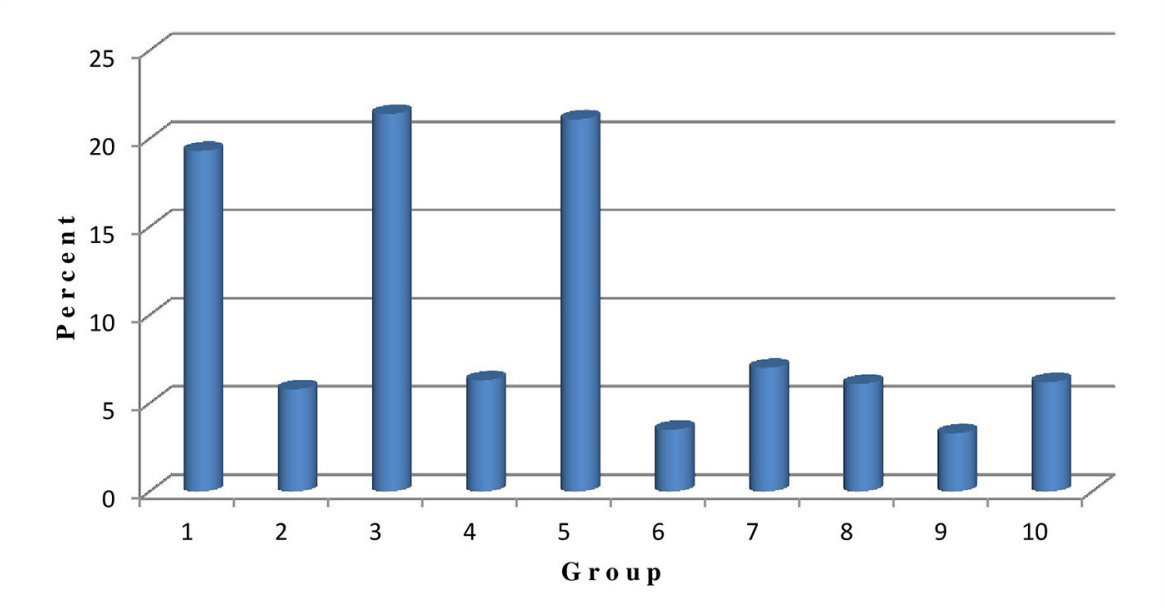

Figure 2 Distribution of Robson group of caesarean section in Hiwot Fana Specialized University Hospital, 2017.

already existing complications and may be less generalisable. Accessing all CS files was difficult due to non-digital archiving of hospital files. Incompleteness of information (history of previous CS, fetal presentation) and incorrect recording of medical registration numbers on logbooks were the reasons for exclusion. We feel that incompleteness of information and inability to locate medical records were not related to any outcomes, and therefore, would not introduce systematic bias. Although the core variables for Robson classification (parity, history of CS, onset of labour, number of fetus, gestational age and fetal lie and presentation) are part of routine obstetric assessment, ${ }^{26}$ the retrospective design of our study may have affected our results because of the incompleteness of the records. We were unable to compute relative size of each Robson groups, and therefore, we cannot say anything about the relative size of each group and are unable to compare women who underwent CS with women who gave birth vaginally.
The performance of CS among low-risk groups (groups 1, 2, 3 and 4) for non-absolute medical indications-fetal compromise and failure to progress-should be further examined. In the majority of facilities, and HFSUH is not an exception, birth monitoring is minimal with a low recording of fetal heart rate on partograph. ${ }^{36}{ }^{37}$ Inadequate facilities for monitoring fetal heart rate and lack of close monitoring are challenges to relying on such indications. ${ }^{38}$ Opportunities for instrumental delivery and training staff to increase its uptake are warranted to decrease primary caesarean among low-risk groups. Limiting the CS rate in low-risk pregnancies is key to lowering the trend of increased CS. ${ }^{39}$ Since TGCS is not an audit of the appropriateness of indications for $\mathrm{CS},{ }^{40}$ a continuous audit of indications for CS should be designed to achieve an optimum level of appropriate CS rates. Possible reasons for the increase in CS among groups 1 and 3 should be explored to decrease overall CS rate and

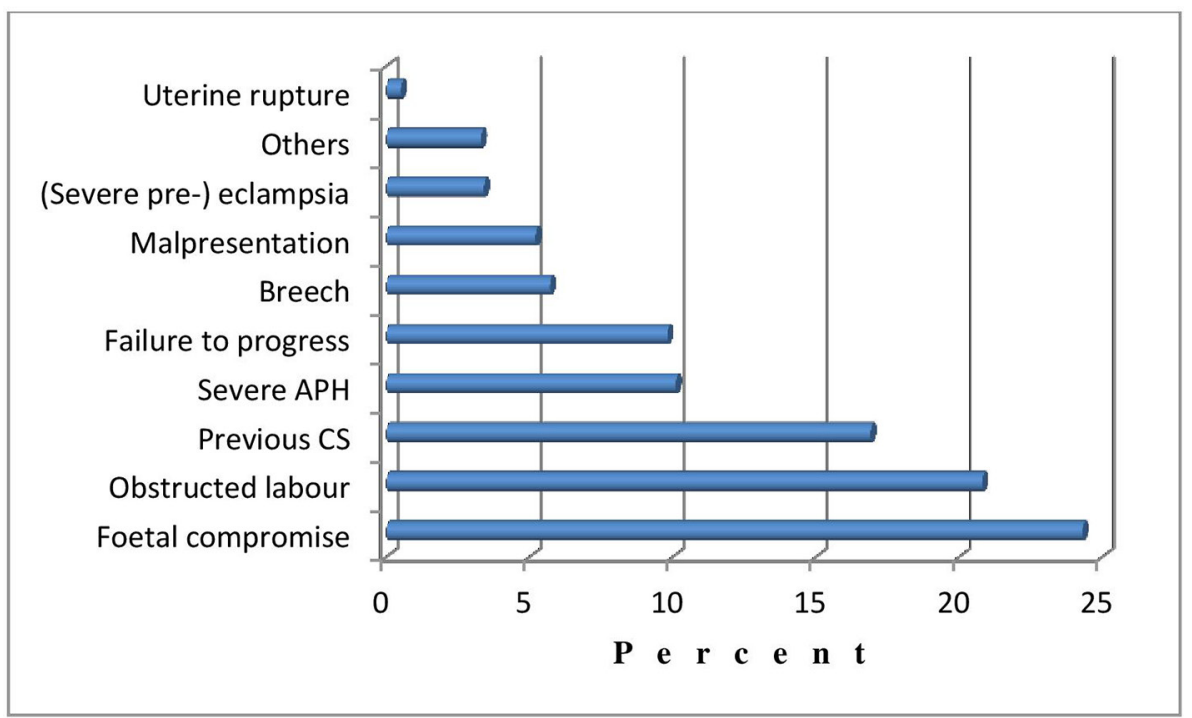

Figure 3 Indications for CS in an Hiwot Fana Specialized University Hospital, 2017. APH, antepartum haemorrhage; CS, caesarean section. 


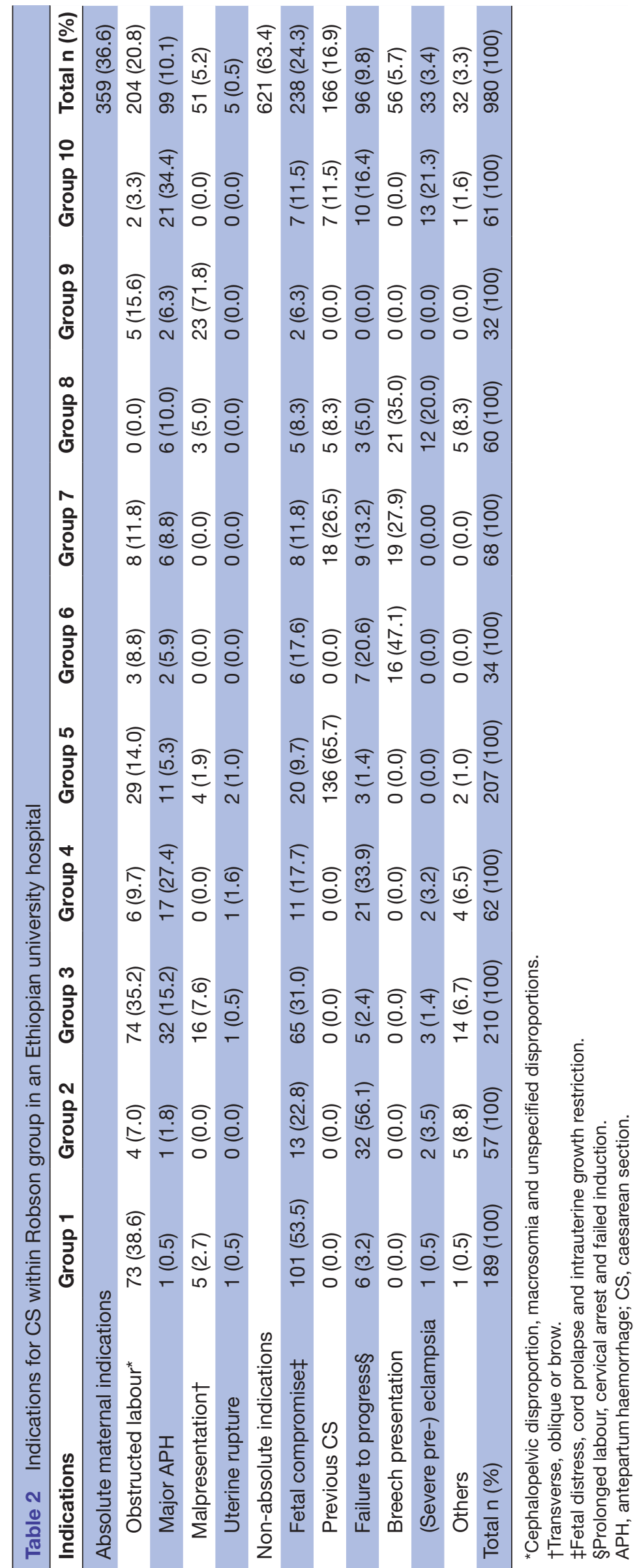




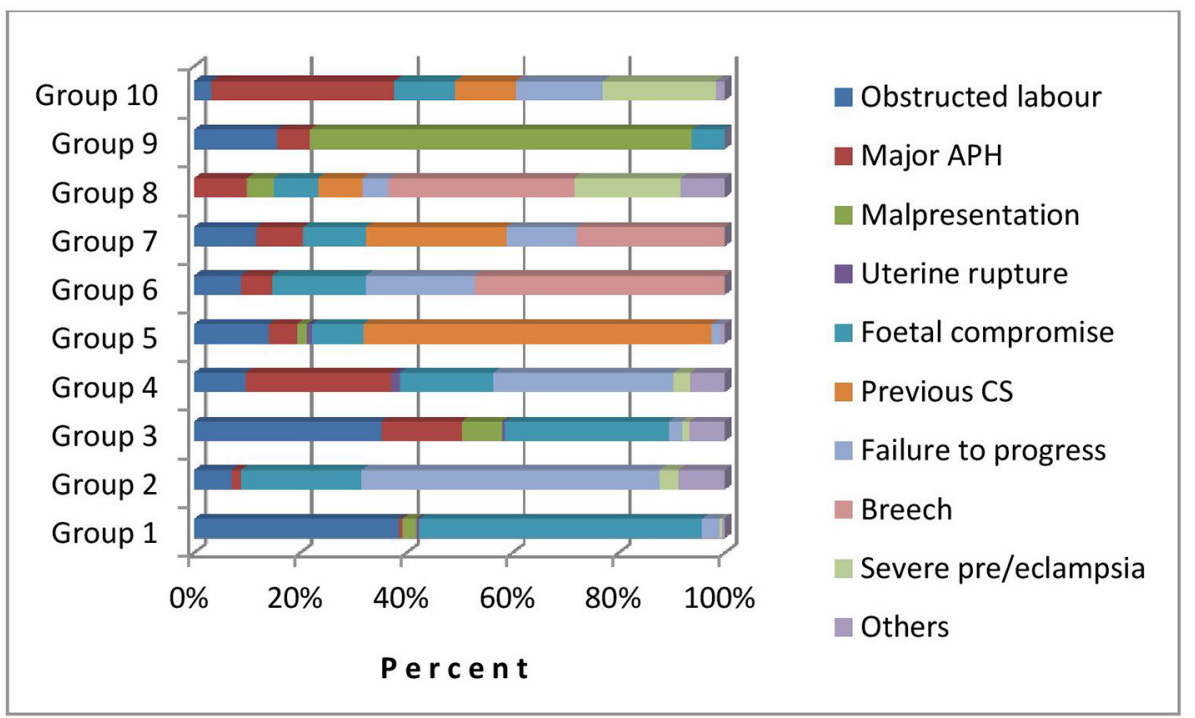

Figure 4 Indications for CS within the 10 groups in a university hospital in eastern Ethiopia. APH, antepartum ha emorrhage; CS, caesarean section.

repeat caesarean in the future (group 5). A prospective study consisting both women who delivered vaginally and through CS is necessary to understand the proportion of CS within each Robson group.

\section{Author affiliations}

${ }^{1}$ School of Nursing and Midwifery, College of Health and Medical Sciences, Haramaya University, Harar, Ethiopia

${ }^{2}$ Department of Obstetrics and Gynaecology, University Medical Centre Groningen, University of Groningen, Groningen, The Netherlands

${ }^{3}$ Faculty of Medical Sciences, University Medical Centre Groningen, University of Groningen, Groningen, The Netherlands

${ }^{4}$ Department of Obstetrics and Gynaecology, Hiwot Fana Specialized University Hospital, Harar, Ethiopia

${ }^{5}$ Department of Obstetrics and Gynaecology, Haramaya University College of Health and Medical Sciences, Harar, Ethiopia

${ }^{6}$ Department of Obstetrics and Gynaecology, Leeuwarden Medical Centre, Leeuwarden, The Netherlands

${ }^{7}$ Department of Global Health, Health Sciences, University Medical Centre Groningen, Groningen, The Netherlands

Acknowledgements We want to thank the hospital managers for creating a conducive environment for conducting this study. We want to extend our thanks to supportive staffs in the maternity unit and card archive room for their support in relocating women's medical files.

Contributors AKT and JS conceived the study and wrote the original draft of the manuscript. OP, MdeM, MS and IK collected data. AKT, TG and JS did the supervision and provided mentorship. Analysis was done by AKT. All authors contributed to the writing and reviewed the article and approved the final version of the manuscript to be published.

Funding AKT received a PhD grant from the Dutch Organisation for Internationalization in Education (NUFFIC).

Disclaimer The funding organisation has no role in the design, execution or decision to publish the study.

Competing interests None declared.

Patient consent Not required.

Ethics approval This study was approved by the institutional health research ethics review committee of College of Health and Medical Sciences, Haramaya University in Ethiopia (ref no: C/A/R/D/01/1681/16).

Provenance and peer review Not commissioned; externally peer reviewed.
Data sharing statement Data essential for conclusion are included in this manuscript. Additional data can be obtained from the corresponding author on reasonable request.

Open Access This is an Open Access article distributed in accordance with the Creative Commons Attribution Non Commercial (CC BY-NC 4.0) license, which permits others to distribute, remix, adapt, build upon this work non-commercially, and license their derivative works on different terms, provided the original work is properly cited and the use is non-commercial. See: http://creativecommons.org/ licenses/by-nc/4.0/

(c) Article author(s) (or their employer(s) unless otherwise stated in the text of the article) 2018. All rights reserved. No commercial use is permitted unless otherwise expressly granted.

\section{REFERENCES}

1. Betrán AP, Ye J, Moller AB, et al. The increasing trend in caesarean section rates: global, regional and national estimates: 1990-2014. PLoS One 2016;11:e0148343.

2. World Health Organization Human Reproduction Programme, 10 April 2015. WHO statement on caesarean section rates. Reprod Health Matters 2015;23:149-50.

3. Ye J, Zhang J, Mikolajczyk R, et al. Association between rates of caesarean section and maternal and neonatal mortality in the 21st century: a worldwide population-based ecological study with longitudinal data. BJOG 2016;123:745-53.

4. Betran AP, Torloni MR, Zhang J, et al. What is the optimal rate of caesarean section at population level? A systematic review of ecologic studies. Reprod Health 2015;12:57.

5. World Health Organization. Reproductive health: managing complications in pregnancy and childbirth: a guide for midwives and doctors. Geneva: World Health Organization, 2003.

6. Rijken MJ, Meguid T, van den Akker T, et al. Global surgery and the dilemma for obstetricians. Lancet 2015;386:1941-2.

7. Belachew J, Cnattingius S, Mulic-Lutvica A, et al. Risk of retained placenta in women previously delivered by caesarean section: a population-based cohort study. BJOG 2014;121:224-9.

8. Kok N, Ruiter L, Hof M, et al. Risk of maternal and neonatal complications in subsequent pregnancy after planned caesarean section in a first birth, compared with emergency caesarean section: a nationwide comparative cohort study. BJOG 2014;121:216-23.

9. Villar J, Carroli G, Zavaleta N, et al. Maternal and neonatal individual risks and benefits associated with caesarean delivery: multicentre prospective study. BMJ 2007;335:1025.

10. Central Statistical Agency (CSA) [Ethiopia] and ICF. Ethiopia Demographic and Health Survey 2016. Addis Ababa, Ethiopia, and Rockville, Maryland, USA. Ethiopia Demographic and Health Survey: CSA and ICF, 2016. 
11. Fesseha N, Getachew A, Hiluf M, et al. A national review of cesarean delivery in Ethiopia. Int J Gynaecol Obstet 2011;115:106-11.

12. Tsega F, Mengistie B, Dessie $Y$, et al. Prevalence of cesarean section in urban health facilities and associated factors in Eastern Ethiopia: hospital based cross sectional study. J Preg Child Health 2015;2:169-73.

13. Gibbons L, Belizan JM, Lauer JA, et al. Inequities in the use of cesarean section deliveries in the world. Am J Obstet Gynecol 2012;206:331.e1-9.

14. Gebremedhin S, Trend GS. Trend and socio-demographic differentials of Caesarean section rate in Addis Ababa, Ethiopia: analysis based on Ethiopia demographic and health surveys data. Reprod Health 2014;11:14.

15. Johnson CT, Johnson TRB, Adanu RMK, et al. Obstetric Surgery. In: Debas HT, Donkor P, Gawande A, eds. Essential Surgery: disease control priorities. 1. Third Edn. Washington (DC): International Bank for Reconstruction and Development / The World Bank, 2015.

16. Stanton C, Ronsmans C. Baltimore Group on Cesarean. Recommendations for routine reporting on indications for cesarean delivery in developing countries. Birth 2008;35:204-11.

17. Torloni MR, Betran AP, Souza JP, et al. Classifications for cesarean section: a systematic review. PLoS One 2011;6:e14566.

18. Robson MS. Can we reduce the caesarean section rate? Best Pract Res Clin Obstet Gynaecol 2001;15:179-94.

19. Brennan DJ, Robson MS, Murphy M, et al. Comparative analysis of international cesarean delivery rates using 10-group classification identifies significant variation in spontaneous labor. Am J Obstet Gynecol 2009;201:308.e1-308.e8.

20. Costa ML, Cecatti JG, Souza JP, et al. Using a caesarean section classification system based on characteristics of the population as a way of monitoring obstetric practice. Reprod Health 2010;7:13,4755.

21. Le Ray $C$, Blondel $B$, Prunet $C$, et al. Stabilising the caesarean rate: which target population? BJOG 2015;122:690-9.

22. Abebe FE, Gebeyehu AW, Kidane AN, et al. Factors leading to cesarean section delivery at Felegehiwot referral hospital Northwest Ethiopia: a retrospective record review. Reprod Health 2016;13:6,015

23. Say L, Souza JP, Pattinson RC, et al. Maternal near miss - towards a standard tool for monitoring quality of maternal health care. Best Pract Res Clin Obstet Gynaecol 2009;23:287-96.

24. Litorp H, Kidanto HL, Nystrom L, et al. Increasing caesarean section rates among low-risk groups: a panel study classifying deliveries according to Robson at a university hospital in Tanzania. BMC Pregnancy Childbirth 2013;13:107,2393.

25. Makhanya V, Govender L, Moodley J. Utility of the Robson Ten Group Classification System to determine appropriateness of caesarean section at a rural regional hospital in KwaZulu-Natal, South Africa. $S$ Afr Med J 2015;105:292-5.
26. World Health Organization. Robson classification: implementation manual. Geneva: World Health Organization, 2017.

27. Loué VA, Gbary EA, Koffi SV, et al. Analysis of caesarean rate and indications of university hospitals in sub-Saharan African developing countries using Robson classification system: the case of Cocody's hospital center, Abidjan-Cote d'Ivoire. IJRCOG 2017:5:1773-7.

28. Kelly S, Sprague A, Fell DB, et al. Examining caesarean section rates in Canada using the Robson classification system. $J$ Obstet Gynaecol Can 2013;35:206-14.

29. Kazmi T, Saiseema S, Khan S. Analysis of cesarean section rate - according to robson's 10-group classification. Oman Med J 2012;27:415-7.

30. Roberge S, Dubé E, Blouin S, et al. Reporting caesarean delivery in Quebec using the Robson classification system. J Obstet Gynaecol Can 2017;39:152-6.

31. Stavrou EP, Ford JB, Shand AW, et al. Epidemiology and trends for Caesarean section births in New South Wales, Australia: a population-based study. BMC Pregnancy Childbirth 2011;11:8,2393.

32. Vogel JP, Souza JP, Gülmezoglu AM. Patterns and Outcomes of Induction of Labour in Africa and Asia: a secondary analysis of the WHO Global Survey on Maternal and Neonatal Health. PLoS One 2013;8:e65612.

33. Zeitlin J, Mohangoo A, Delnorn M, et al. European perinatal health report. The health and care of pregnant women and babies in Europe in 2013;2010.

34. Rayburn WF, Zhang J. Rising rates of labor induction: present concerns and future strategies. Obstet Gynecol 2002;100:164-7.

35. Vogel JP, Moore JE, Timmings C, et al. Barriers, facilitators and priorities for implementation of who maternal and perinatal health guidelines in four lower-income countries: a great network research activity. PLoS One 2016;11:e0160020.

36. Markos D, Bogale D. Documentation status of the modified World Health Organization partograph in public health institutions of Bale zone, Ethiopia. Reprod Health 2015;12:81,015.

37. Yisma E, Dessalegn B, Astatkie A, et al. Completion of the modified World Health Organization (WHO) partograph during labour in public health institutions of Addis Ababa, Ethiopia. Reprod Health 2013;10:10-23.

38. van Roosmalen J, van der Does CD. Caesarean birth rates worldwide. A search for determinants. Trop Geogr Med 1995;47:19-22.

39. Delbaere I, Cammu H, Martens E, et al. Limiting the caesarean section rate in low risk pregnancies is key to lowering the trend of increased abdominal deliveries: an observational study. BMC Pregnancy Childbirth 2012;12:3.

40. Robson M. The Ten Group Classification System (TGCS) - a common starting point for more detailed analysis. BJOG 2015;122:701. 